\title{
Current concepts and future approaches to vestibular rehabilitation
}

\author{
Fredrik Tjernström ${ }^{1} \cdot$ Oz Zur $^{2,3} \cdot$ Klaus Jahn $^{4,5}$
}

Received: 19 July 2015/Revised: 16 September 2015/ Accepted: 18 September 2015

(C) The Author(s) 2015. This article is published with open access at Springerlink.com

\begin{abstract}
Over the last decades methods of vestibular rehabilitation to enhance adaptation to vestibular loss, habituation to changing sensory conditions, and sensory reweighting in the compensation process have been developed. However, the use of these techniques still depends to a large part on the educational background of the therapist. Individualized assessment of deficits and specific therapeutic programs for different disorders are sparse. Currently, vestibular rehabilitation is often used in an unspecific way in dizzy patients irrespective of the clinical findings. When predicting the future of vestibular rehabilitation, it is tempting to foretell advances in technology for assessment and treatment only, but the current intense exchange between clinicians and basic scientists also predicts advances in truly understanding the complex interactions between the peripheral senses and central adaptation mechanisms. More research is needed to develop reliable techniques to measure sensory dependence
\end{abstract}

This manuscript is part of a supplement sponsored by the German Federal Ministry of Education and Research within the funding initiative for integrated research and treatment centers.

Klaus Jahn

klaus.jahn@med.uni-muenchen.de

1 Department of Oto-Rhino-Laryngology, Head and Neck Surgery, Clinical Sciences, Lund University, Lund, Sweden

2 Department of Physical Therapy, Ben Gurion University of the Negev, Beer Sheva, Israel

3 The Israeli Center for Treating Dizziness and Balance Disorders, Raanana, Israel

4 German Center for Vertigo and Balance Disorders, LudwigMaximilians-University of Munich, Munich, Germany

5 Department of Neurology, Schön Klinik Bad Aibling, Kolbermoorer Str. 72, 83043 Bad Aibling, Germany and to learn how this knowledge can be best used-by playing off the patient's sensory strength or working on the weakness. To be able using the emerging concepts, the neuro-otological community must strive to educate physicians, physiotherapists and nurses to perform the correct examinations for assessment of individual deficits and to look for factors that might impede rehabilitation.

Keywords Adaptation · Habituation · Sensory reweighting $\cdot$ Vestibular rehabilitation

\section{Introduction}

Vestibular rehabilitation is a broad concept that not only implies compensation training after a vestibular lesion or disease, but also postural training and compensation in other causes of vertigo, dizziness or general unsteadiness. It covers a wide clinical area, in which central nervous adaptation mechanisms to a sensory loss or mismatch are vital. To guide training, it is equally important using the right tools for assessments of sensory function, sensory weighting and identification of factors that might protract compensation. The need for knowledge of methods and concepts for vestibular and postural rehabilitation should not be underestimated. In developed countries, the cost associated with falls is high and with an aging population it is a mounting problem that will demand huge resources from hospitals, as well as from the community. In Sweden ( $<10 \mathrm{M}$ inhabitants), the annual cost from falls (2009) amounted to 1.4 billion euro, of which almost 500 million were direct costs and 900 million were related to deterioration in quality of life. These costs are expected to increase to approximately 2.2 billion euro by 2050 if the situation continues to develop at its present rate [1]. 
Abnormal performance on balance tests is the second most important intrinsic predictor for falls in elderly [2], and $35 \%$ of people above 40 years of age have vestibular dysfunction [3].

Acute vestibular loss is the most studied condition and compensation follows certain well-defined steps. The first compensation process consists of central vestibular adaptation, in which the symptoms of acute vestibular loss (spontaneous nystagmus, head and ocular tilt, postural disequilibrium, altered vestibulo-ocular and spinal reflexes [4]), are diminished within the first week due to cerebellar modulation (inhibition [5]) of the initial asymmetric activity of the vestibular nuclei $[6,7]$. The symptoms gradually resolve and the spinal imbalance normalizes and behavioral recovery is initiated $[4,8]$ in a process where plastic changes of the activity of the vestibulocerebellum are essential [7, 9]. However, the dynamic loss of vestibular reflexes persists and remains functionally inadequate and asymmetric [10]. It should be mentioned that the rebalancing of the vestibular nuclei is not only a consequence of cerebellar inhibition but also of direct cellular and synaptic adaptations within the vestibular nuclei. This is important as must drugs used in the early phase of an acute vestibular syndrome do interact directly with binding site in the vestibular nuclei (e.g., histaminergic, GABAergic, glutamatergic receptors). The second stage consists of sensory reweighting, in which the importance of each sensory system (vision, somatosensation and vestibular) for maintaining postural control is reevaluated and changed $[11,12]$. The sensory systems overlap in terms of detection of motion frequency and share some properties of the feedforward mechanisms involved in maintaining postural control. In that sense, the normal postural control system is redundant and sensory systems are able to replace each other. The last stage is continuous sensory calibration and formation of internal feed-forward models generated by everyday activities and from specific postural training.

Rehabilitation therapy consists of exercises that train the sensory systems to interact and be integrated within the central nervous system to provide the correct spatial cues for position as well as for head and body motion. Today we know that vestibular training follows the same kind of Hebbian learning as general memory formation [13], where the experiences from exercises are consolidated during inactivity and thus strengthened (Fig. 1) [14, 15]. The central nervous system processes or plasticity can be enhanced by difficult or challenging exercises [16] for many, but not all patients. In patients with anxiety-related dizziness, the central adaptation processes as well as the sensory-integration processes within the brain are fundamentally affected. In these cases, difficult postural exercises might be counter-productive [17].

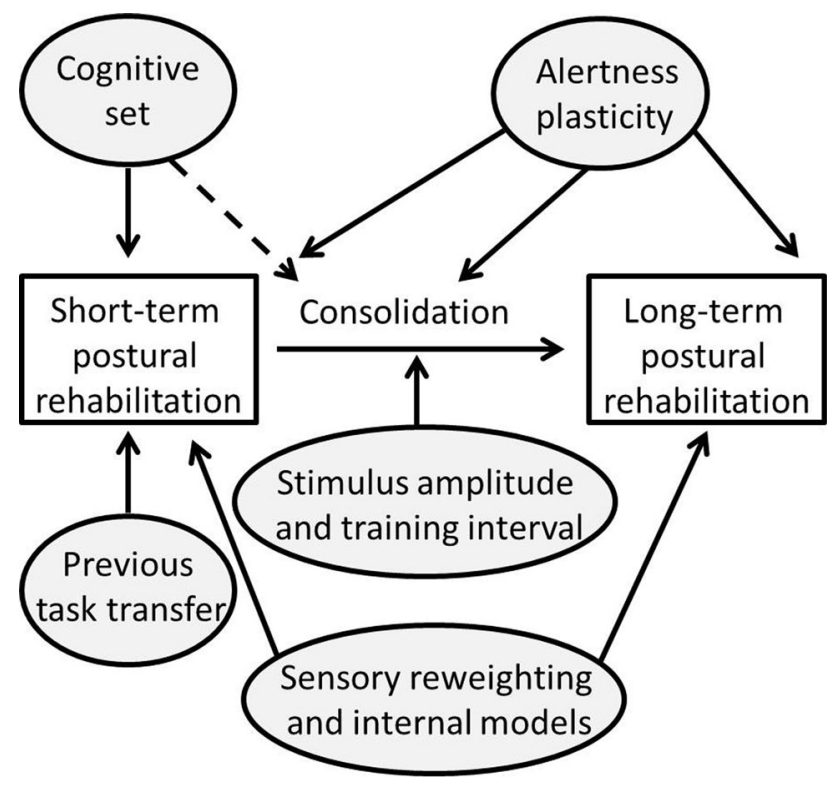

Fig. 1 Postural learning or rehabilitation follows the same processes as general memory formation, i.e., from short-term to long-term learning through the process of consolidation, in which the training experiences are reprocessed during inactivity [14]. The process is affected by the cognitive state of mind (e.g. anxiety [17]) and by central nervous plasticity $[59,60]$ and impeded by reduced alertness from sedatives [61] or sleep deprivation [62]. When designing rehabilitation exercises, it is important to take into account that one exercise might affect succeeding exercises [63], and that the exercises themselves must be sufficiently challenging to promote learning [16, 63]. Learning might be through sensory reweighting or formation of internal models, i.e., motor programs whose output consists of preformed neuromuscular strategies activated automatically or voluntarily in given situations (anticipated movements) [64]

\section{Assessing sensory strategies}

To plan the right rehabilitation strategy, it is crucially important to be able to correctly assess sensory function and weighting of the dizzy patient and thus the sensory strategy of an individual. All rehabilitation programs aim at training the remaining senses to strengthen their interactions, as well as their integration in the brain balance network. For most patients, reweighting is beneficial, but some become over-reliant on a certain sensory system and thus suffer from sensory mismatch [18]. The most flagrant example of this maladaptation is the concept of "visual vertigo" or secondary "phobic postural vertigo" [19], i.e., that visual stimuli induce illusions of self-motion or an erroneous spatial orientation [20-22]. Accordingly, in a demanding environment, it is significantly more difficult for these patients to ignore visual stimulations even when they are asked to focus on a stationary target [23]. Although the concept of sensory reweighting is widely accepted, it is difficult to measure or even assess reliably. The most widely used clinical test for sensory dependence 
is the Romberg test, (comparing postural sway when the eyes are opened vs. closed). In posturography, a ratio can be calculated between the tests which has been labeled both as an index of visual dependence [12] and as somatosensory dependence [24]. One problem with calculating ratios is that variations or changes could be artifacts from small variations in either the denominator or the numerator. Because of the sensory overlap, the innate ability to change postural strategy, at least in easy postural tasks, and adaptation to difficult postural tasks $[14,15]$ (the subjects could have more or less postural sway in any condition), yields low consistency in the sensory profile of an individual when tested repeatedly [25].

The sensory organization test (SOT) in Equitest posturography is often used to appreciate individual sensory weighting in the postural control system [24]. The SOT consists of a series of postural challenges of increasing complexity, which have been shown to correspond to sensory deficits. Ratios from the different conditions are often labeled as indices of vestibular, visual and somatosensory weighting. Measuring different conditions during stance and gait often helps to identify factors contributing to unsteadiness [26, 27]. However, these measures have not been validated between labs and are therefore not available everywhere. This makes the results difficult to interpret when it comes to sensory weighting. The tests also induce central adaptation, which stresses the need for additional methods to assess sensory reweighting [15]. Other evaluations for appreciating visual dependency are the rod and frame and rod and disk tests [28, 29]. The results from these tests have rarely been compared to posturography measurements, but there are definite correlations between the tests in patients suffering from visual vertigo, that validates the rod and disk test, at least in the subgroup of dizzy patients [30].

\section{Factors impeding rehabilitation}

Factors that protract compensation and prolong subjective symptoms have to be recognized early to prevent development of chronic unsteadiness. It is important to screen for risk factors for a prolonged course of compensation after acute vestibular lesions as for example advanced age, medication, microvascular brain lesions and preexisting sensory deficits. Concepts like "Functional dizziness", persistent postural-perceptual dizziness (PPPD) [31], phobic postural vertigo (PPV), and chronic subjective dizziness (CSD) have helped to advance knowledge of the relationship between anxiety/depression and dizziness. Patients suffering from one of these overlapping syndromes have been shown to interpret sensory cues incorrectly [32]. By doing so the postural control system in unchallenged conditions is already extended to the point that they do not learn or adapt to postural training $[17,33]$. These factors compromise rehabilitation. It has also been shown that if the diagnosis is delayed, the condition will be harder to cure [34]. Various treatments have been tried, e.g., regular vestibular exercises combined with cognitive behavioral therapy. Although the short-term results are promising, the long-term result is less convincing so far [35]. Retrospective studies on anxiolytic drugs and antidepressants have shown beneficial effects, especially if the original triggering disease was vestibular [36]. Considering the incidence of the condition and the ensuing functional disability, randomized controlled studies on treatment of phobic dizziness and vertigo are urgently needed. Muscular pain and tension are important conditions that co-exist with dizziness and result in protracted disability, as well as distorted spatial orientation and dizziness [3739]. Chronic pain also results in central sensitization [40], which is very much in line with motion sensitivity observed in dizzy patients.

\section{Future aspects of vestibular rehabilitation}

In all probability, the health care systems, at least in developed countries, will not receive greater funding for preventing falls or for rehabilitating dizzy patients. With the aging of the population, we will thus need to accomplish more for less money. Engaging in physical activity prior to a sensory loss is beneficial for rehabilitation [41], which implies that the entire population should be encouraged to be physically active and that the beneficial aspects of activities probably outweigh the cost of subsidization. As physicians and physiotherapists, we also need to anticipate when rehabilitation will be needed and prehabilitate patients who might suffer from sensory loss (e.g., before vestibular surgery or other interventions that result in vestibular deafferentation, but also in chronic vestibular disorders such as Menière's disease) [42].

For most patients, standard exercises after a vestibular loss will be sufficient to achieve subjective compensation. In the future, new sets of exercises will also focus on creating a mismatch between the sensory systems to which patients have to adapt [43]. However, we need a greater variety of exercises that meet the demands of the individuals' sensory strategy. Currently, most exercises involve static visual cues that are used for visual recalibration of spatial and postural orientation. However, every day activities involve eye tracking of moving targets, while at the same time moving the head and body, which highlights the need for developing suitable, sufficiently complex exercises [44, 45]. Ideally, the individual patient should be mapped for his/her sensory strategy and then treated with different subsets of exercises that challenge him or her [46, 47]. Additional research for individualization of rehabilitation is of the utmost importance. Despite the wide 
acceptance of the hypothesis of sensory reweighting, virtually no research is being conducted to determine whether exercises should be designed to augment an individual's sensory strength (e.g., visually dependency) or to boost the weakness (vestibular loss). With new methods of measuring vestibular function, i.e., the quantitative head impulse test [48], phenomena like the covert saccade have been discovered in patients with a deficient vestibulo-ocular reflex [49]. A covert saccade is an eye saccade that occurs during the head movement in the head impulse test, mimicking the vestibulo-ocular reflex. Its exact origin is unknown, although it has been suggested to involve a cervico-ocular reflex or an anticipatory strategy for the eyes to focus on the target and not wait for the system to react to the nonexistent vestibular information [50]. The presence of covert saccades suggests that the vestibular dysfunction has been compensated and eye-head coordination anticipates movements in real life situations. Thereby, an alternate strategy has been formed, which could be interpreted as better compensation, or compensation beyond vestibular only strategies.

The future will increasingly involve smart-phone applications for exercises, monitoring and possibly for diagnostic purposes, as well as institutional and homebased virtual reality exercise programs [51, 52]. The mobile applications are already developed and will possibly soon be available for treatment outside of the laboratory or the care giver's office. The gyro that is built in most smart-phones can be used for feed-back guided postural training in virtual reality, much in the same way as larger devices are able to do today (e.g., Wii-Fit ${ }^{\circledR}$ ). The applications will rapidly be further developed and used for postural feedback training in real life situations. For instance the concept of geo-tagging could be applied for these programs, i.e., in "real" reality walk a specific route, fraught with postural and sensory challenges that would be beneficial for the particular individual. Applications have also the great advantage to monitor progress or lack thereof at a distance and will likely be cost beneficial.

Patients with balance problems and difficulties walking due to vestibular deficits might also benefit from recent developments in robot-assisted gait training [53-55]. Exoskeletons with and without treadmill support (e.g., Hocoma Lokomat ${ }^{\circledR}$, Eksobionics Ekso GT $^{\circledR}$ ) allow high repetition rates and are therefore beneficial to re-learn automated gait patterns. End-effector based systems (e.g., Ectron $\mathrm{Geo}^{\circledR}$ ) can simulate any gait pattern and allow the training of stair climbing and other demanding conditions.

Lastly, replacement and modulation of the deficient vestibular system are emerging areas of research. Modulation of activity of vestibular afferents, namely by noisy galvanic stimulation is a promising area, not only in vestibular rehabilitation. It has been shown that information processing in a variety of sensory systems can be enhanced by adding an imperceptible amount of noise to the sensor afferents [56]. The rationale behind this is the stochastic resonance in sensory systems. Accordingly it was shown that subthreshold noise input to the vestibular system is able to improve postural balance in healthy subjects and patients with vestibular loss [57]. It can be expected that neuro-modulation techniques like noisy galvanic vestibular stimulation will increasingly be used in the near future to enhance sensory functions. Vestibular implants have been developed using different approaches to restore the lacking vestibular function. Current results demonstrate that electrical stimulation with implants is a safe and can activate the vestibular system [58]. However, it is not clear which patients will have a benefit from surgery and to which extent relevant aspects like quality of life, functioning, and participation will improve. Further, in a heterogeneous patient population with very different etiologies and disease durations the right patients have to chosen for invasive procedures.

In summary, we expect the programs of vestibular rehabilitation to become more specific in the future. The interaction between clinicians and basic scientists, as well as high standards for the professional education of physical therapists will ensure the development of new rehabilitation programs based on pathophysiological concepts. Emerging technologies including mobile sensors, on demand training using mobile apps, training in virtual environments, the use of neuro-modulation, and the development of vestibular implants will further enlarge the spectrum of therapies available for dizzy patients (Fig. 2).

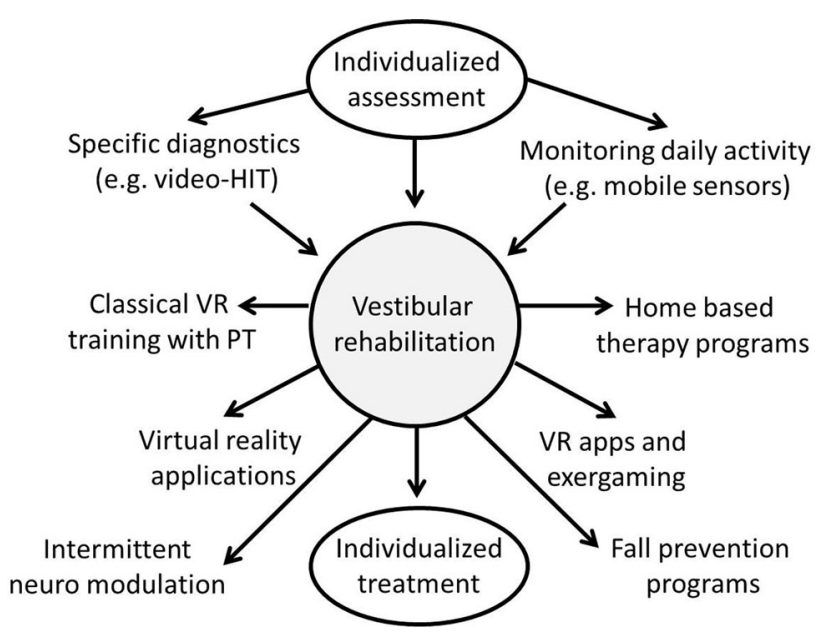

Fig. 2 Summary of trends in vestibular rehabilitation. Individualized assessment of deficits is the prerequisite for individualized treatment. New technologies and modern assessment will support the development of disease specific programs. HIT head impulse test, $P T$ physical therapist, $V R$ vestibular rehabilitation 


\section{Compliance with ethical standards}

Conflicts of interest The authors declare that there is no conflict of interest. The work was supported by the Federal Ministry of Education and Research in Germany (BMBF IFB 01EO1401).

Ethical standard This article does not contain any studies with human participants or animals performed by any of the authors.

Open Access This article is distributed under the terms of the Creative Commons Attribution 4.0 International License (http://crea tivecommons.org/licenses/by/4.0/), which permits unrestricted use, distribution, and reproduction in any medium, provided you give appropriate credit to the original author(s) and the source, provide a link to the Creative Commons license, and indicate if changes were made.

\section{References}

1. Gyllensvärd H (2010) Cost effectivness of injury prevention-a systematic review of municipality based interventions. Cost Eff Resour Alloc 8:17

2. Gillespie LD, Robertson MC, Gillespie WJ, Sherrington C, Gates S, Clemson LM, Lamb SE (2012) Interventions for preventing falls in older people living in the community. Cochrane Database Syst Rev 9:CD007146

3. Agrawal Y, Carey JP, Della Santina CC, Schubert MC, Minor LB (2009) Disorders of balance and vestibular function in US adults: data from the National Health and Nutrition Examination Survey, 2001-2004. Arch Intern Med 169:938-944

4. Cullen KE, Minor LB, Beraneck M, Sadeghi SG (2009) Neural substrates underlying vestibular compensation: contribution of peripheral versus central processing. J Vestib Res 19:171-182

5. McCabe BF, Ryu JH (1969) Experiments on vestibular compensation. Laryngoscope 79:1728-1736

6. Lacour M, Xerri C, Hugon M (1979) Compensation of postural reactions to fall in the vestibular neurectomized monkey. Role of the remaining labyrinthine afferences. Exp Brain Res 37:563-580

7. Kitahara T, Takeda N, Kiyama H, Kubo T (1998) Molecular mechanisms of vestibular compensation in the central vestibular system-review. Acta Otolaryngol Suppl 539:19-27

8. Lacour M, Roll JP, Appaix M (1976) Modifications and development of spinal reflexes in the alert baboon (Papio papio) following an unilateral vestibular neurotomy. Brain Res 113:255-269

9. Courjon JH, Flandrin JM, Jeannerod M, Schmid R (1982) The role of the flocculus in vestibular compensation after hemilabyrinthectomy. Brain Res 239:251-257

10. Curthoys IS (2000) Vestibular compensation and substitution. Curr Opin Neurol 13:27-30

11. Schieppati M, Schmid M, Sozzi S (2014) Rapid processing of haptic cues for postural control in blind subjects. Clin Neurophysiol 125:1427-1439

12. Lacour M, Barthelemy J, Borel L, Magnan J, Xerri C, Chays A, Ouaknine M (1997) Sensory strategies in human postural control before and after unilateral vestibular neurotomy. Exp Brain Res 115:300-310

13. Hebb DO (1949) The organization of behavior; a neuropsychological theory. Wiley, New York

14. Tjernstrom F, Fransson PA, Hafstrom A, Magnusson M (2002) Adaptation of postural control to perturbations-a process that initiates long-term motor memory. Gait Posture 15:75-82

15. Wrisley DM, Stephens MJ, Mosley S, Wojnowski A, Duffy J, Burkard R (2007) Learning effects of repetitive administrations of the sensory organization test in healthy young adults. Arch Phys Med Rehabil 88:1049-1054

16. Mahncke HW, Bronstone A, Merzenich MM (2006) Brain plasticity and functional losses in the aged: scientific bases for a novel intervention. Prog Brain Res 157:81-109

17. Tjernstrom F, Fransson PA, Holmberg J, Karlberg M, Magnusson M (2009) Decreased postural adaptation in patients with phobic postural vertigo - an effect of an "anxious" control of posture? Neurosci Lett 454:198-202

18. Dieterich M (2004) Dizziness. Neurologist 10:154-164

19. Brandt T, Huppert D, Dieterich M (1994) Phobic postural vertigo: a first follow-up. J Neurol 241:191-195

20. Azulay JP, Mesure S, Amblard B, Pouget J (2002) Increased visual dependence in Parkinson's disease. Percept Mot Skills 95:1106-1114

21. Isableu B, Fourre B, Vuillerme N, Giraudet G, Amorim MA (2011) Differential integration of visual and kinaesthetic signals to upright stance. Exp Brain Res 212:33-46

22. Pavlou M, Davies RA, Bronstein AM (2006) The assessment of increased sensitivity to visual stimuli in patients with chronic dizziness. J Vestib Res 16:223-231

23. Zur O, Dickstein R, Dannenbaum E, Carmeli E, Fung J (2014) The influence of visual vertigo and vestibulopathy on oculomotor responses. J Vestib Res 24:305-311

24. Furman JM (1994) Posturography: uses and limitations. Baillieres Clin Neurol 3:501-513

25. Tjernstrom F, Bjorklund M, Malmstrom EM (2015) Romberg ratio in quiet stance posturography-Test to retest reliability. Gait Posture 42:27-31

26. Krafczyk S, Tietze S, Swoboda W, Valkovic P, Brandt T (2006) Artificial neural network: a new diagnostic posturographic tool for disorders of stance. ClinNeurophysiol 117:1692-1698

27. Wuehr M, Pradhan C, Novozhilov S, Krafczyk S, Brandt T, Jahn K, Schniepp R (2013) Inadequate interaction between open- and closed-loop postural control in phobic postural vertigo. J Neurol 260:1314-1323

28. Isableu B, Ohlmann T, Cremieux J, Amblard B (1997) Selection of spatial frame of reference and postural control variability. Exp Brain Res 114:584-589

29. Hafstrom A, Fransson PA, Karlberg M, Magnusson M (2004) Ipsilesional visual field dependency for patients with vestibular schwannoma. NeuroReport 15:2201-2204

30. Guerraz M, Yardley L, Bertholon P, Pollak L, Rudge P, Gresty MA, Bronstein AM (2001) Visual vertigo: symptom assessment, spatial orientation and postural control. Brain 124:1646-1656

31. Staab JP, Eckhardt-Henn A, Horii A, Jacob R, Strupp M (2014) Progress report of the Behavioral Subcommittee of the Committee on Classification of the Bárány Society. J Vestib Res 24:93-94

32. Odman M, Maire R (2008) Chronic subjective dizziness. Acta Otolaryngol 128:1085-1088

33. Holmberg J, Tjernstrom F, Karlberg M, Fransson PA, Magnusson M (2009) Reduced postural differences between phobic postural vertigo patients and healthy subjects during a postural threat. J Neurol 256:1258-1262

34. Huppert D, Strupp M, Rettinger N, Hecht J, Brandt T (2005) Phobic postural vertigo-a long-term follow-up (5 to 15 years) of 106 patients. J Neurol 252:564-569

35. Holmberg J, Karlberg M, Harlacher U, Magnusson M (2007) One-year follow-up of cognitive behavioral therapy for phobic postural vertigo. J Neurol 254:1189-1192

36. Staab JP, Ruckenstein MJ, Solomon D, Shepard NT (2002) Serotonin reuptake inhibitors for dizziness with psychiatric symptoms. Arch Otolaryngol Head Neck Surg 128:554-560

37. Karlberg M, Magnusson M, Malmstrom EM, Melander A, Moritz U (1996) Postural and symptomatic improvement after 
physiotherapy in patients with dizziness of suspected cervical origin. Arch Phys Med Rehabil 77:874-882

38. Malmstrom EM, Karlberg M, Melander A, Magnusson M, Moritz U (2007) Cervicogenic dizziness-musculoskeletal findings before and after treatment and long-term outcome. Disabil Rehabil 29:1193-1205

39. Malmstrom EM, Westergren H, Fransson PA, Karlberg M, Magnusson M (2013) Experimentally induced deep cervical muscle pain distorts head on trunk orientation. Eur J Appl Physiol 113:2487-2499

40. Huntley AH, Srbely JZ, Zettel JL (2015) Experimentally induced central sensitization in the cervical spine evokes postural stiffening strategies in healthy young adults. Gait Posture 41:652-657

41. Gauchard GC, Parietti-Winkler C, Lion A, Simon C, Perrin PP (2013) Impact of pre-operative regular physical activity on balance control compensation after vestibular schwannoma surgery. Gait Posture 37:82-87

42. Tjernstrom F, Fransson PA, Kahlon B, Karlberg M, Lindberg S, Siesjo P, Magnusson M (2009) Vestibular PREHAB and gentamicin before schwannoma surgery may improve long-term postural function. J Neurol Neurosurg Psychiatry 80:1254-1260

43. Herdman SJ, Clendaniel RA, Mattox DE, Holliday MJ, Niparko JK (1995) Vestibular adaptation exercises and recovery: acute stage after acoustic neuroma resection. Otolaryngol Head Neck Surg 113:77-87

44. Byl N, Zhang W, Coo S, Tomizuka M (2015) Clinical impact of gait training enhanced with visual kinematic biofeedback: patients with Parkinson's disease and patients stable post stroke. Neuropsychologia. doi:10.1016/j.neuropsychologia.2015.04.020

45. Aquaroni Ricci N, Aratani MC, Caovilla HH, Freitas Gananca F (2012) Effects of conventional versus multimodal vestibular rehabilitation on functional capacity and balance control in older people with chronic dizziness from vestibular disorders: design of a randomized clinical trial. Trials 13:246

46. Keshner EA, Slaboda JC, Buddharaju R, Lanaria L, Norman J (2011) Augmenting sensory-motor conflict promotes adaptation of postural behaviors in a virtual environment. Conf Proc IEEE Eng Med Biol Soc 2011:1379-1382

47. Deveze A, Montava M, Lopez C, Lacour M, Magnan J, Borel L (2015) Vestibular compensation following vestibular neurotomy. Eur Ann Otorhinolaryngol Head Neck Dis. doi:10.1016/j.anorl. 2015.04.003

48. MacDougall HG, Weber KP, McGarvie LA, Halmagyi GM, Curthoys IS (2009) The video head impulse test: diagnostic accuracy in peripheral vestibulopathy. Neurology 73:1134-1141

49. Weber KP, Aw ST, Todd MJ, McGarvie LA, Curthoys IS, Halmagyi GM (2008) Head impulse test in unilateral vestibular loss: vestibulo-ocular reflex and catch-up saccades. Neurology 70:454-463

50. Tjernstrom F, Nystrom A, Magnusson M (2012) How to uncover the covert saccade during the head impulse test. Otol Neurotol 33:1583-1585

51. Krpic A, Savanovic A, Cikajlo I (2013) Telerehabilitation: remote multimedia-supported assistance and mobile monitoring of balance training outcomes can facilitate the clinical staff's effort. Int J Rehabil Res 36:162-171

52. Meldrum D, Herdman S, Vance R, Murray D, Malone K, Duffy D, Glennon A, McConn-Walsh R (2015) Effectiveness of conventional versus virtual reality-based balance exercises in vestibular rehabilitation for unilateral peripheral vestibular loss: results of a randomised controlled trial. Arch Phys Med Rehabil. doi:10.1016/j.apmr.2015.02.032

53. Hesse S, Schmidt H, Werner C, Bardeleben A (2003) Upper and lower extremity robotic devices for rehabilitation and for studying motor control. Curr Opin Neurol 16:705-710

54. Swinnen E, Beckwée D, Meeusen R, Baeyens JP, Kerckhofs E (2014) Does robot-assisted gait rehabilitation improve balance in stroke patients? A systematic review. Top Stroke Rehabil 21:87-100

55. Mehrholz J, Pohl M. Electromechanical-assisted gait training after stroke: a systematic review comparing end-effector and exoskeleton devices. J Rehabil Med 44:193-199

56. Moss F, Ward LM, Sannita WG (2004) Stochastic resonance and sensory information processing: a tutorial and review of application. Clin Neurophysiol 115:267-281

57. Iwasaki S, Yamamoto Y, Togo F, Kinoshita M, Yoshifuji Y, Fujimoto C, Yamasoba T (2014) Noisy vestibular stimulation improves body balance in bilateral vestibulopathy. Neurology 82:969-975

58. Guinand N, van de Berg R, Cavuscens S, Stokroos RJ, Ranieri M, Pelizzone M, Kingma H, Guyot JP, Perez-Fornos A (2015) Vestibular implants: 8 years of experience with electrical stimulation of the vestibular nerve in 11 patients with bilateral vestibular loss. ORL J Otorhinolaryngol Relat Spec 77:227-240

59. Tjernstrom F, Oredsson J, Magnusson M (2006) A "wait and learn" strategy of postural control learning in children? J Vestib Res 16:257-264

60. Sehm B, Taubert M, Conde V, Weise D, Classen J, Dukart J, Draganski B, Villringer A, Ragert P (2014) Structural brain plasticity in Parkinson's disease induced by balance training. Neurobiol Aging 35:232-239

61. Beck R, Gunther L, Xiong G, Potschka H, Boning G, Bartenstein $\mathrm{P}$, Brandt T, Jahn K, Dieterich M, Strupp M, la Fougere C, Zwergal A (2014) The mixed blessing of treating symptoms in acute vestibular failure-evidence from a 4-aminopyridine experiment. Exp Neurol 261:638-645

62. Patel M, Gomez S, Berg S, Almbladh P, Lindblad J, Petersen H, Magnusson M, Johansson R, Fransson PA (2008) Effects of 24-h and 36-h sleep deprivation on human postural control and adaptation. Exp Brain Res 185:165-173

63. Tjernstrom F, Fransson PA, Patel M, Magnusson M (2010) Postural control and adaptation are influenced by preceding postural challenges. Exp Brain Res 202:613-621

64. Merfeld DM, Zupan LH (2002) Neural processing of gravitoinertial cues in humans. III. Modeling tilt and translation responses. J Neurophysiol 87:819-833 